\title{
Spectra evolution over on-vine holding of Italia table grapes: prediction of maturity and discrimination for harvest times using a Vis-NIR hyperspectral device
}

\author{
Francesca Piazzolla, Maria Luisa Amodio, Giancarlo Colelli \\ Department of Science of Food, Agriculture and Environment, University of Foggia, Italy
}

\begin{abstract}
Measurement of certain grape quality parameters (sugars, acidity, and $\mathrm{pH}$-value) is essential for the determination of the optimum harvest time. Non-destructive analytical techniques, including near infrared (NIR) spectroscopy, can be valid alternatives to traditional analytical methods for the determination of maturity indexes, enabling the possibility of on-field applications. This work aims to study the reliability to monitor spectra changes related with ripening of table grapes and to select optimal wavelengths for the discrimination of bunches from different harvests, in addition to the prediction of total soluble solids, $\mathrm{pH}$, titratable acidity, phenols and antioxidant activity of table grapes. Grapes were harvested four times from the same plants at day 0 (I HT), and after 11 (II HT), 27 (III HT) and 48 (IV HT) days. Spectra were acquired from the images obtained using a spectral scanner Vis-NIR (ver 1.4.; DV Srl, Padova, Italy), with a detector in the region between $400-1000 \mathrm{~nm}$ principal component analysis was used to remove outliers followed by spectra pre-treatment. The best prediction model was achieved for soluble solids with the regression coefficient values of 0.91 for calibration and 0.88 for validation followed by titratable acidity $(0.71$ and 0.78$)$ and antioxidant activity ( 0.68 and 0.62$)$. In addition an excellent correlation was observed between spectra and days before harvest $\left(\mathrm{R}^{2}\right.$ of 0.98 for calibration and prediction models) indicating that is possible to relate spectra changes with ripening, leading also to the effective discrimination of the fruits from the different harvest times. The results showed that this technique may be a valid sup-
\end{abstract}

Correspondence: Maria Luisa Amodio, Department of Science of Food, Agriculture and Environment, University of Foggia, via Napoli 25, 71122 Foggia, Italy.

E-mail: marialuisa.amodio@unifg.it

Key words: Hyperspectral; partial least squares regression; linear discriminant analysis; classification.

Received for publication: 25 November 2016.

Accepted for publication: 25 January 2017.

(C) Copyright F. Piazzolla et al., 2017

Licensee PAGEPress, Italy

Journal of Agricultural Engineering 2017; XLVIII:639

doi:10.4081/jae.2017.639

This article is distributed under the terms of the Creative Commons Attribution Noncommercial License (by-nc 4.0) which permits any noncommercial use, distribution, and reproduction in any medium, provided the original author(s) and source are credited. port to select the optimal harvest time also based on the prediction of the maturity related constituents.

\section{Introduction}

According to a report of the Food and Agriculture Organisation (FAO) the table grapes are among the most widely consumed fruits in the world with $27 \%$ of the total grape production being used as fresh fruits (FAO, 2009). Many factors contribute towards consumer acceptability of table grapes including size, shape, colour, skin thickness, crispiness, flesh firmness, brightness, colour uniformity, berry size, flavour, nutritional content, maturity stage and harvest time (Cliff et al., 1996; Crisosto et al., 2003; Piva et al., 2006). The factors of cardinal significance in this regard are total soluble solids (TSS), titratable acidity (TA), and TSS/TA ratio, representing the major contributing factors towards acceptable ripeness (Guelfat-Reich and Safran, 1971; Peppi et al., 2006; Jayasena and Cameron, 2008). Most of the researchers use total soluble TSS, TA, colour and volatile compounds as commercial harvest ripening indices (Sonego et al., 2002; Wei et al., 2002).

The measurement of these quality parameters using the destructive instrumental and analytical practices require expert labour, the use of chemical agents, and costly equipments. Despite being time consuming and expensive, these analytical techniques provide analysis for a limited number of samples, therefore, present researchers in the field of postharvest are oriented towards non-destructive food techniques which are fast, and allow to analyse a higher number of samples and repetitions of the same sample in real time (Costa et al., 2009). Many studies have successfully implemented non-destructive analytical techniques for the prediction of the quality attributes of various fruits and vegetables (Slaughter et al., 1996; Pedro and Ferreira, 2007; Chia et al., 2012; Ignat et al., 2012).

In case of grapes, TSS, $\mathrm{pH}$, TA, phenolic content, sugar content and antioxidant activity lied in the sphere of interest of many researches due to the significant relation of these analytes with the grape and wine quality, in fact most of them have been studied for wine grapes whereas literature on table grapes is scarce.

González-Caballero et al. (2010), achieved high $\mathrm{R}^{2}$ values of 0.89 and 0.87 for the TSS and reducing sugar content with the standard error of cross validation (SECV) of $1.41^{\circ}$ Brix and $17.13 \mathrm{~g} / \mathrm{L}$, respectively. Reducing sugar content study during the stages of grape ripening, wine making and ageing was conducted by FernándezNovales et al. (2009). González-Caballero et al. (2011) also studied the changes in the internal quality attributes of wine grapes and excellent precision was obtained for TSS and reducing sugars with an $\mathrm{R}^{2}$ as high as 0.94 and good precision was obtained for $\mathrm{pH}$, TA, malic acid and tartaric acid with $\mathrm{R}^{2}$ values ranging from 0.73 to 0.87 . 
Dambergs et al. (2006) found that the predictions of the $\mathrm{pH}$ and anthocyanins were based on the visible range and those for the TSS were based on the near infrared (NIR) range. The sugar content of the grapes using portable Vis-NIR devices have also been measured, as in a study conducted by $\mathrm{Wu}$ et al. (2008); the reflectance spectra of the grape berries were collected in the VisNIR range obtaining an $\mathrm{R}^{2}$ of prediction of 0.908 with a root mean square error of prediction (RMSEP) of $0.112 \mathrm{~g} / \mathrm{L}$.

Nogales-Bueno et al. (2014) used the NIR in the range of 900$1700 \mathrm{~nm}$ for non-destructive prediction of phenolic content of grape skin, TSS, TA and $\mathrm{pH}$ developing both individual models and global models. The values of $\mathrm{R}^{2}$ for for the individual models of these parameters were very high (more than 0.90) for red grapes. Encouraging values were achieved for the global model, with $\mathrm{R}^{2}=0.77$ and $\mathrm{SEP}=1.97 \mathrm{mg} \mathrm{g}^{-1}$ for phenolic content in grape skin; 0.97 and $1.61^{\circ}$ Brix for sugars; 0.96 and $3.89 \mathrm{~g} \mathrm{~L}^{-1}$ for TA, and 0.92 and 0.18 , for $\mathrm{pH}$. One other study evaluated the feasibility of using hyperspectral imaging in the Vis-NIR range for the prediction of anthocyanins, polyphenols, sugars and density (González-Caballero et al., 2012). Other works also predicted phenolic content including flavonols (Ferrer-Gallego et al., 2011) and anthocyanins (Fernandes et al., 2011) of wine grapes. Moreover fructose and glucose concentration, $\mathrm{pH}$ value, TA and glycerol, gluconic acid and acetic acid were also predicted with on-line near Vis-NIR spectrometer upon grape reception at wineries (Porep et al., 2015). As for table grapes, few works are available, and only predicting maturity indexes; Baiano et al. (2012) applied hyperspectral imaging for the determination of TA and TSS for table grapes. Satisfactory $\mathrm{R}^{2}$ were found for white and red grapes being 0.95 and 0.82 in case of TA, 0.94 and 0.93 for TSS and 0.80 and 0.90 for $\mathrm{pH}$.

In addition, Piazzolla et al. (2013) evaluated the feasibility of using spectral Vis-NIR images to discriminate table grapes from different harvest times and reported excellent potential of this technique, being able to correctly classify almost all samples (non error rate of $99 \%$ ).

Since most of the work refers to wine grapes, the objective of this work was to evaluate the feasibility of using spectral information to characterise table grape quality (including relevant nutritional parameters) also in relation to different harvest times in terms of internal components.

Particularly this work aimed to use spectral information in the Vis-NIR range, obtained with an innovative hyperspectral scanner, for a comprehensive study of ripening changes of table grapes over on-vine holding by exploring the feasibility of: i) predicting soluble solids content, $\mathrm{pH}$, titratable acidity, phenols and antioxidant activity; ii) monitoring the correlation of spectra changes with the time of on vine holding; iii) selecting the most relevant wavelengths for the discrimination of fruit from different harvest times.

\section{Materials and methods}

\section{Experimental design}

First harvest of table grapes of the variety cv. Italia, grown in location Cellamare (Province of Bari, Italy), was done on the $8^{\text {th }}$ of October, 2010 (I HT) followed by subsequent harvests after 11 (II HT), 27 (III HT) and 48 (IV HT) days. The first harvest time corresponded to the commercial maturity, according to grower decision, whereas the following were aimed to monitor quality of onvine held grapes, since in Southern Italy is a very common practice postponing the harvest up to Christmas. Grapes were cultivated with the Apulia canopy grape system and covered with net and low-density polyethylene plastic film with $170 \mu \mathrm{m}$ thickness. At the first harvest 15 plants were marked in a row of the field, according to grower indications, and at each harvest time, 2 bunches per plant were harvested (for a total of 30 bunches) and transported to the Postharvest Laboratory of the University of Foggia.

Fifteen berries from each bunch were randomly selected, and used for chemical analysis after the acquisition of hyperspectral images. The berries were then squeezed obtaining one sample juice for each bunch, simulating the commercial procedure applied to decide the moment to harvest based on the juice of some bunches. Correspondingly, the spectra were averaged for a total of $120 \mathrm{spec}-$ tra ( 2 bunches $\times 15$ plants $\times 4$ harvest times), one for each sample juice.

\section{Quality determination}

After each harvest the maturity stage and nutritional content of the grapes were determined by recording the values of TSS, TA, $\mathrm{pH}$, antioxidant activity and total phenol content by destructive analysis of the grape juice obtained from each bunch. Moreover colour and berry firmness were also monitored, to characterise differences at harvest. A digital refractometer (Atago PR32-Palette; ATAGO CO., Ltd., Tokyo, Japan) was used to measure the TSS; measurements of $\mathrm{pH}$ and TA, expressed in percentage of tartaric acid, were carried out with an automatic titrator (TitroMatic CRISON 1S; Crison Instrument, Barcelona, Spain). For measuring phenol content and antioxidant activity, $5 \mathrm{~g}$ of berries were homogenised with an Ultraturrax (IKA T18 basic; IKA ${ }^{\circledR}$-Werke $\mathrm{GmbH} \&$ Co. KG, Staufen, Germany) after the addition of $3 \times 10^{3}$ $\mathrm{mg} \mathrm{kg}^{-1}$ of methanol plus $3 \%$ formic acid. The extracts were then centrifuged at $5^{\circ} \mathrm{C}$ and $9000 \mathrm{rpm}$ for $10 \mathrm{~min}$. Total phenols were determined according to the method of Singleton and Rossi (1965). Each extract $(100 \mu \mathrm{L})$ was mixed with $1.58 \mathrm{~mL}$ water, $100 \mu \mathrm{L}$ of Folin-Ciocalteu reagent and $300 \mu \mathrm{L}$ of sodium carbonate solution (200 $\left.\mathrm{g} \mathrm{L}^{-1}\right)$. After $2 \mathrm{~h}$ standing in the dark, the absorbance of the solution was read at $725 \mathrm{~nm}$ against a blank using a spectrophotometer (UV-1700; Shimadzu Corp., Jiangsu, China). The content of total phenols was calculated on the basis of the calibration curve of gallic acid and was expressed as grams of gallic acid per kilogram of fresh weight $\left(\mathrm{g} \mathrm{GA} \mathrm{kg}^{-1}\right)$. Antioxidant assay was performed following the procedure described by Brand-Williams et al. (1995) with minor modifications. The diluted sample $(50 \mu \mathrm{L})$ was pipetted into $0.95 \mathrm{~mL}$ of diphenylpicrylhydrazyl solution to initiate the reaction. The absorbance was read after $24 \mathrm{~h}$ at $515 \mathrm{~nm}$. Trolox (6-Hydroxy-2, 5, 7, 8-tetramethylchromane-2-carboxylic acid) was used as a standard and the antioxidant activity was reported in milligrams of Trolox equivalents per kilogram of fresh weight $\left(\mathrm{g} \mathrm{TE} \mathrm{kg}^{-1}\right)$. Firmness was determined on 15 berries for each cluster and defined as the force $(\mathrm{N})$ required to compress each berry for $3 \mathrm{~mm}$ between two parallel plates using an Instron Universal Testing Machine (model 3343; Instron Inc., Norwood, MA, USA), at a speed of $50 \mathrm{~mm} / \mathrm{min}$. Colour information were extracted as described in the following paragraph.

A one-way analysis of variance was performed on quality attributes at harvest and mean values were separated with Tukey's test $(\mathrm{P}<0.05)$. Data were analysed with the StatGraphics Centurion software (v. 16.1.11; StatPoint Technologies, Inc., Warrenton, VA, USA).

\section{Vis-NIR spectral acquisition}

Hyperspectral imaging (v. 1.4.5; DV Srl, Padova, Italy) system consisted of a charge-coupled device (CCD), a 12-bit camera con- 
nected to a V10 type spectrograph (400-1000 nm, $25 \mu \mathrm{m}$ slit, resolution $5 \mathrm{~nm}$; ImSpector V10, Specim Ltd., Haarlem, The Netherlands) coupled with a standard C-mount f16 mm lens. The optics of this imaging system helped to study the fruit properties associated to the spectral range of 400-1000 nm of reflectance with $5 \mathrm{~nm}$ of resolution. The target was placed at a distance of $360 \mathrm{~mm}$ from the camera. The light source consisted of a $150 \mathrm{~W}$ halogen lamp (EKE $21 \mathrm{~V} 150 \mathrm{~W}$, Tokyo, Japan) mounted at an angle of $45^{\circ}$ to the horizontal plane, and of an optic fibre that transfers the radiation to a linear light diffuser. The camera spectrograph assembly was supplied with a stepper motor to move the unit through the field of view of the camera and carry out a line-by-line scan of the sample. The spectral images were collected in a dark room where the halogen light was the only light source. One scan per sample, for 15 randomly selected berries per bunch was done with an acquisition speed of $3 \mathrm{~mm} \mathrm{~s}^{-1}$ in the Vis-NIR range. The analysis was performed on fruits conditioned at room temperature (approx. $\left.20^{\circ} \mathrm{C}\right)$.

The hyperspectral images were first corrected with a white and a dark reference. The dark reference was used to remove the effect of dark current of the CCD detectors that are thermally sensitive. All the spectra were extracted using the company software, SS scanner v. 1.3.4.6. (DV Srl). A region of interest corresponding to the maximum inscribed rectangle was manually selected on each berry and then the spectra of the 15 berries corresponding to a single bunch were averaged. The software also allowed to automatic calculate $L^{*}, a^{*}, b^{*}$ colour values and the Hue Angle was then calculated, as following:

$$
H=\operatorname{arctg} \frac{b^{*}}{a^{*}}
$$

\section{Spectra processing and modelling}

The acquired spectral data were analysed using the Unscrambler packing software version 9.1 (CAMO ASA, Oslo, Norway). All the reflectance measurements were first transformed to absorbance values using $\log (1 / \mathrm{R})$ according to the law of Lambert-Beer. The spectra were analysed with a principal component analysis central model to identify and eliminate defective spectral outliers.

Spectra were then pre-treated by different mathematical methods. Pre-treatment methods [smoothing; multiple scatter correction (MSC); Savitzky-Golay derivative; baseline; standard normal variate] tested individually and in combination on the whole dataset.

A partial least squares regression (PLS) algorithm was applied after each transformation to select the best transformation for the prediction TSS, $\mathrm{pH}$, TA, phenols and antioxidant activity, using all 121 wavelengths.

Particularly, PLS model seeks to correlate spectral variations (X) with defined value (Y), and each component is obtained by maximising the covariance between $\mathrm{Y}$ and all possible linear functions of $\mathrm{X}$. This leads to components, which are more directly related to variability in $\mathrm{Y}$ than are original variables.

After selection of the best transformation, calibration and prediction models were developed. From the total of 120 spectra, 80 samples were randomly selected for the calibration data set and 40 for the prediction data set. The performance of the PLS regression, was evaluated by comparing values of coefficient of correlation (R) for calibration, the root mean square error of calibration (RMSEC), the coefficient of correlation for cross validation (RSECV), the root mean square error of cross validation (RMSECV), the standard error of prevision (SEP) and RMSEP.

In addition, a linear discriminant analysis (LDA) was tested with the aim of discriminating bunches from the 4 harvest times, using a forward stepwise model. This model first reviews all the

Table 1. Quality parameters of Italia table grapes at different harvest times.

\begin{tabular}{|c|c|c|c|c|c|}
\hline \multirow[t]{2}{*}{ Parameter } & & \multicolumn{4}{|c|}{ Harvest times } \\
\hline & & I HT & II HT & III HT & IV HT \\
\hline TSS ( ${ }^{\circ}$ Brix) & $\begin{array}{l}\text { Mean } \\
\text { Range } \\
\text { SD }\end{array}$ & $\begin{array}{c}18.25^{\mathrm{a}} \\
15.75-19.78 \\
1.43\end{array}$ & $\begin{array}{c}17.18^{\mathrm{a}} \\
14.55-18.38 \\
1.26\end{array}$ & $\begin{array}{c}17.60^{\mathrm{a}} \\
13.03-19.83 \\
1.8\end{array}$ & $\begin{array}{c}18.24^{\mathrm{a}} \\
13.80-20.18 \\
1.77\end{array}$ \\
\hline $\mathrm{pH}$ value & $\begin{array}{l}\text { Mean } \\
\text { Range } \\
\text { SD }\end{array}$ & $\begin{array}{c}3.95^{\mathrm{b}} \\
3.88-4.26 \\
0.15\end{array}$ & $\begin{array}{c}4.01^{\mathrm{b}} \\
3.75-4.23 \\
0.12\end{array}$ & $\begin{array}{c}4.06^{\mathrm{b}} \\
3.78-4.25 \\
0.14\end{array}$ & $\begin{array}{c}4.2^{4 a} \\
3.83-4.59 \\
0.16\end{array}$ \\
\hline Titratable acidity (tartaric ac. g/100 g) & $\begin{array}{l}\text { Mean } \\
\text { Range } \\
\text { SD }\end{array}$ & $\begin{array}{c}0.39^{\mathrm{a}} \\
0.27-0.48 \\
0.04\end{array}$ & $\begin{array}{c}0.33^{b} \\
0.28-0.40 \\
0.04\end{array}$ & $\begin{array}{c}0.32^{\mathrm{b}} \\
0.27-0.38 \\
0.03\end{array}$ & $\begin{array}{c}0.32^{\mathrm{b}} \\
0.30-0.38 \\
0.02\end{array}$ \\
\hline Phenols (gallic ac. mg/100 g) & $\begin{array}{l}\text { Mean } \\
\text { Range } \\
\text { SD }\end{array}$ & $\begin{array}{c}55.37^{\mathrm{a}} \\
34.91-87.39 \\
17.28\end{array}$ & $\begin{array}{c}33.38^{b} \\
22.67-42.88 \\
0.25\end{array}$ & $\begin{array}{c}38.39^{\mathrm{b}} \\
25.00-60.20 \\
9.88\end{array}$ & $\begin{array}{c}42.53^{\mathrm{b}} \\
21.46-72.03 \\
15.29\end{array}$ \\
\hline Antioxidant activity (Trolox mg/100 g) & $\begin{array}{l}\text { Mean } \\
\text { Range } \\
\text { SD }\end{array}$ & $\begin{array}{c}279.82^{\mathrm{a}} \\
228.13-343.49 \\
42.67\end{array}$ & $\begin{array}{c}179.15^{c} \\
144.92-211.92 \\
24.32\end{array}$ & $\begin{array}{c}189.44^{c} \\
148.52-265.09 \\
42.43\end{array}$ & $\begin{array}{c}230.91^{\mathrm{b}} \\
179.82-315.15 \\
34.74\end{array}$ \\
\hline Firmness (N) & $\begin{array}{l}\text { Mean } \\
\text { Range } \\
\text { SD } \\
\end{array}$ & $\begin{array}{c}7.35^{\mathrm{a}} \\
5.50-12.32 \\
1.72\end{array}$ & $\begin{array}{c}6.62^{\mathrm{b}} \\
4.23-10.45 \\
1.51\end{array}$ & $\begin{array}{c}6.70^{\mathrm{b}} \\
5.14-9.96 \\
1.43\end{array}$ & $\begin{array}{c}6.89^{\mathrm{b}} \\
4.49-10.75 \\
1.6\end{array}$ \\
\hline Hue angle $\left(^{\circ}\right)$ & $\begin{array}{l}\text { Mean } \\
\text { Range } \\
\text { SD }\end{array}$ & $\begin{array}{c}110.59^{\mathrm{a}} \\
107.59-113.13 \\
0.53\end{array}$ & $\begin{array}{c}108.33^{\mathrm{ab}} \\
104.50-111.86 \\
1.99\end{array}$ & $\begin{array}{c}106.47^{\mathrm{b}} \\
102.63-109.03 \\
2.15\end{array}$ & $\begin{array}{c}100.43^{c} \\
94.75-104.97 \\
3.54\end{array}$ \\
\hline
\end{tabular}

HT, harvest time; TSS, total soluble solids; SD, standard deviation. ${ }^{\mathrm{a}-c}$ Within each column different letters indicate mean values significantly different $(\mathrm{P}<0.05)$. 
variables and includes, step by steps, the ones that have the biggest weight for the discrimination between groups. In this way 14 wavelengths were selected over 121 . Using only these 14 wavelengths was also possible to find correlation between absorbance spectra and days of grapes holding on the vine, starting from the first harvest (0 days) up to the last harvest (48 days).

\section{Results and discussion}

\section{Grape composition}

Table 1 shows the evolution of quality parameters as harvesting proceeded over time. Harvest time influenced all quality attributes except TSS. Titratable acidity decreased during ripening, with grapes of I HT showing a higher TA $(0.39 \%$ tartaric acid $)$ than grapes from the other harvest times (about $0.32 \%$ ); accordingly $\mathrm{pH}$ increased with the harvest date from 3.95 to 4.24 , with the last harvest being significantly higher than the previous 3 . Furthermore, it can be also observed that also the phenols decreased during ripen- ing, and particularly after the I HT (55.37 gallic ac. mg/100 g). Antioxidant activity did not follow a linear trend, with the proceeding of the ripening presenting highest values at I HT (279 mg/100 $\mathrm{g}$ ), then decreasing at II HT (about $179.1 \mathrm{mg} / 100 \mathrm{~g}$ ), and then increasing again at III HT (about $189.4 \mathrm{mg} / 100 \mathrm{~g}$ ) and at IV HT $(230 \mathrm{mg} / 100 \mathrm{~g})$. Firmness decreased during the ripening reporting the highest value at I HT (7.35). Also the hue angle decreased significantly during the ripening, starting from 110.50 up to 100.43 at the last harvest; this changes indicated a loss of the green component which can be associated to the chlorophyll degradation and a consequent increase of the yellow component.

\section{Calibration and external prediction developments}

Principal component analysis did not reveal the presence of spectra outliers, according to the values of the Mahalanobis distance $(\mathrm{H})$, using a threshold of 3.0, therefore, the number of analysed samples was 120. In Figure 1 are shown the raw 120 spectra. The whole dataset, was then used to select the best pre-treatment for each quality parameter. The selected results of the model obtained with the best transformations for each quality attribute, are shown in Table 2.

Table 2. Calibration and cross validation partial least squares regression models for total soluble solids, pH, titratable acidity, total phenols and antioxidant activity of Italia table grapes $(n=120)$ using different mathematical pre-treatments.

\begin{tabular}{|c|c|c|c|c|c|c|c|c|c|}
\hline Parameter & Pre-treatment & SD & $R_{\text {cal }}$ & RMSEC & SEC & RCV & RMSECV & SECV & PLS factors \\
\hline TSS ( ${ }^{\circ}$ Brix) & $\begin{array}{l}\text { No transformation } \\
\text { Smoothing S. Golay } \\
\text { MSC } \\
1^{\circ} \text { Der. S. Golay } \\
2^{\circ} \text { Der. S. Golay } \\
\text { Baseline } \\
\text { SNV }\end{array}$ & $\begin{array}{l}1.56 \\
1.47 \\
1.56 \\
1.71 \\
1.33 \\
1.64 \\
1.64\end{array}$ & $\begin{array}{l}0.06 \\
0.05 \\
0.06 \\
0.01 \\
0.00 \\
0.06 \\
0.06\end{array}$ & $\begin{array}{l}0.04 \\
0.06 \\
0.05 \\
0.06 \\
0.07 \\
0.07 \\
0.07\end{array}$ & $\begin{array}{l}0.04 \\
0.06 \\
0.04 \\
0.06 \\
0.09 \\
0.07 \\
0.07\end{array}$ & $\begin{array}{l}0.43 \\
0.04 \\
0.04 \\
0.05 \\
0.03 \\
0.00 \\
0.04\end{array}$ & $\begin{array}{l}0.08 \\
0.08 \\
0.08 \\
0.08 \\
0.10 \\
0.05 \\
0.08\end{array}$ & $\begin{array}{l}0.08 \\
0.08 \\
0.08 \\
0.05 \\
0.10 \\
0.05 \\
0.08\end{array}$ & $\begin{array}{c}11 \\
11 \\
11 \\
13 \\
5 \\
13 \\
13\end{array}$ \\
\hline $\mathrm{pH}$ & $\begin{array}{l}\text { No transformation } \\
\text { Smoothing S. Golay } \\
\text { MSC } \\
1^{\circ} \text { Der. S. Golay } \\
2^{\circ} \text { Der. S. Golay } \\
\text { Baseline } \\
\text { SNV }\end{array}$ & $\begin{array}{l}0.12 \\
0.11 \\
0.11 \\
0.12 \\
0.11 \\
0.11 \\
0.11\end{array}$ & $\begin{array}{l}0.55 \\
0.60 \\
0.55 \\
0.62 \\
0.57 \\
0.58 \\
0.56\end{array}$ & $\begin{array}{l}0.16 \\
0.15 \\
0.16 \\
0.15 \\
0.16 \\
0.15 \\
0.16\end{array}$ & $\begin{array}{l}0.16 \\
0.15 \\
0.16 \\
0.15 \\
0.16 \\
0.16 \\
0.16\end{array}$ & $\begin{array}{l}0.60 \\
0.55 \\
0.50 \\
0.53 \\
0.50 \\
0.52 \\
0.52\end{array}$ & $\begin{array}{l}0.15 \\
0.16 \\
0.15 \\
0.16 \\
0.17 \\
0.16 \\
0.16\end{array}$ & $\begin{array}{l}0.15 \\
0.16 \\
0.17 \\
0.16 \\
0.17 \\
0.16 \\
0.16\end{array}$ & $\begin{array}{l}3 \\
3 \\
2 \\
3 \\
2 \\
3 \\
2\end{array}$ \\
\hline $\begin{array}{l}\text { Titratable acidity } \\
\text { (tartaric ac. g/100 g) }\end{array}$ & $\begin{array}{l}\text { No transformation } \\
\text { Smoothing S. Golay } \\
\text { MSC } \\
1^{\circ} \text { Der. S. Golay } \\
2^{\circ} \text { Der. S. Golay } \\
\text { Baseline } \\
\text { SNV }\end{array}$ & $\begin{array}{l}0.03 \\
0.02 \\
0.03 \\
0.02 \\
0.02 \\
0.03 \\
0.03\end{array}$ & $\begin{array}{l}0.71 \\
0.69 \\
0.73 \\
0.64 \\
0.64 \\
0.71 \\
0.72\end{array}$ & $\begin{array}{l}0.04 \\
0.04 \\
0.03 \\
0.04 \\
0.04 \\
0.04 \\
0.04\end{array}$ & $\begin{array}{l}0.04 \\
0.04 \\
0.03 \\
0.04 \\
0.04 \\
0.04 \\
0.04\end{array}$ & $\begin{array}{l}0.62 \\
0.60 \\
0.62 \\
0.56 \\
0.53 \\
0.60 \\
0.60\end{array}$ & $\begin{array}{l}0.04 \\
0.04 \\
0.04 \\
0.04 \\
0.04 \\
0.04 \\
0.04\end{array}$ & $\begin{array}{l}0.04 \\
0.04 \\
0.04 \\
0.04 \\
0.04 \\
0.04 \\
0.04\end{array}$ & $\begin{array}{l}7 \\
7 \\
7 \\
3 \\
3 \\
8 \\
7\end{array}$ \\
\hline Phenols (gallic ac. mg/100 g) & $\begin{array}{l}\text { No transformation } \\
\text { Smoothing S. Golay } \\
\text { MSC } \\
1^{\circ} \text { Der. S. Golay } \\
2^{\circ} \text { Der. S. Golay } \\
\text { Baseline } \\
\text { SNV }\end{array}$ & $\begin{array}{l}4.09 \\
4.08 \\
6.78 \\
6.63 \\
7.17 \\
6.73 \\
6.08\end{array}$ & $\begin{array}{l}0.14 \\
0.23 \\
0.37 \\
0.37 \\
0.40 \\
0.37 \\
0.34\end{array}$ & $\begin{array}{l}17.95 \\
17.59 \\
16.74 \\
16.80 \\
16.58 \\
16.76 \\
17.00\end{array}$ & $\begin{array}{l}18.02 \\
16.66 \\
16.81 \\
16.87 \\
16.65 \\
16.83 \\
17.08\end{array}$ & $\begin{array}{l}0.23 \\
0.12 \\
0.27 \\
0.27 \\
0.27 \\
0.27 \\
0.21\end{array}$ & $\begin{array}{l}17.59 \\
18.01 \\
17.47 \\
17.51 \\
17.53 \\
17.53 \\
17.79\end{array}$ & $\begin{array}{l}17.66 \\
18.09 \\
17.55 \\
17.59 \\
17.60 \\
17.60 \\
17.87\end{array}$ & $\begin{array}{l}1 \\
1 \\
3 \\
2 \\
2 \\
3 \\
2\end{array}$ \\
\hline Antioxidant activity (Trolox mg/100 g) & $\begin{array}{l}\text { No transformation } \\
\text { Smoothing S. Golay } \\
\text { MSC } \\
1^{\circ} \text { Der. S. Golay } \\
2^{\circ} \text { Der. S. Golay } \\
\text { Baseline } \\
\text { SNV }\end{array}$ & $\begin{array}{l}41.88 \\
40.96 \\
41.34 \\
41.88 \\
40.07 \\
42.07 \\
39.04\end{array}$ & $\begin{array}{l}0.67 \\
0.65 \\
0.66 \\
0.67 \\
0.64 \\
0.67 \\
0.62\end{array}$ & $\begin{array}{l}46.52 \\
47.32 \\
47.00 \\
46.52 \\
48.08 \\
46.35 \\
48.90\end{array}$ & $\begin{array}{l}46.71 \\
47.52 \\
47.19 \\
46.71 \\
48.28 \\
46.54 \\
49.11 \\
\end{array}$ & $\begin{array}{l}0.56 \\
0.55 \\
0.58 \\
0.57 \\
0.54 \\
0.57 \\
0.55\end{array}$ & $\begin{array}{l}52.32 \\
53.00 \\
51.38 \\
51.54 \\
52.81 \\
52.06 \\
52.39\end{array}$ & $\begin{array}{l}52.54 \\
53.19 \\
51.59 \\
51.75 \\
53.04 \\
52.27 \\
52.60\end{array}$ & $\begin{array}{l}7 \\
5 \\
5 \\
3 \\
3 \\
6 \\
4\end{array}$ \\
\hline
\end{tabular}

$\mathrm{SD}$, standard deviation; $R_{c a l}$ R value for calibration set; RMSEC, root mean square error of calibration; SEC, square error of calibration; $R_{C V}$, R values for cross-validation set; RMSECV, root mean square error of cross validation; SECV, coefficient of correlation for cross validation; PLS, partial least squares regression; TSS, total soluble solids; MSC, multiplicative scatter correction; SNV, standard normal variate. 
Based on the highest $R$ and the lowest RMSEC, the first Savitzky-Golay derivative was the optimal transformation for TSS and $\mathrm{pH}$, with $R$ values of 0.90 and 0.62 respectively in calibration, and 0.67 and 0.53 , in cross validation. Figure 2 shows the plot between the regression coefficients and the wavelengths for the calibration of total soluble solids; it can be observed that throughout the length of the spectral range there are many wavelengths relevant for the final prediction. As for $\mathrm{pH}$ highest regression coefficients were detected at 695, 870 and 905 (data not shown). For TA and antioxidant activity, MSC was found to be the optimal pretreatment giving an $R$ value of 0.73 and 0.66 in calibration and 0.62 and 0.58 , respectively in cross validation.

For phenols, the best mathematical transformation was the second Savitzky-Golay derivative, with $R$ value of 0.40 in calibration and 0.27 in cross-validation. The maximum peaks contributing to the model performance were observed at 420, 445 and $720 \mathrm{~nm}$ (data not shown).

Table 3 shows the statistics for the calibration and for the prediction model of TSS, $\mathrm{pH}$, TA, total phenols, and antioxidant activity when using external samples not included in the calibration, while in the Figure 3 are shown the performance of the models of prediction for each quality attributes by optimal pre-treatment. Model for predicting soluble solids presented a very satisfactory performance, with a value of $R_{\text {cal }}$ of $0.91, R M S E C$ of $0.77^{\circ} \mathrm{Brix}$, while the value of $R_{\text {pred }}$ was found to be 0.88 , with $R M S E P$ of $0.95^{\circ}$ Brix. As for residual prediction deviation, the obtained value close to 2 (1.92) indicates that that coarse quantitative predictions are possible by using the model (Nicolaï et al., 2007). These results were similar to those reported in the studies of Cao et al. (2010) in which the TSS of grape berries belonging to three different varieties were measured by using 2 different model development techniques i.e., PLS and genetic algorithm coupled with least square support vector machine (GA-LS-SVM). The obtained values of $\mathrm{R}$ of prediction were approximately equal to the values obtained in the present study being 0.91 for both PLS and GA-LS-SVM with RMSEP of 0.93 and $0.96^{\circ}$ Brix. The results of the present study were also comparable to those of another study conducted by Baiano et al. (2012) using the same device. These authors predicted the TSS of red and white grape berries with a value of $\mathrm{R}^{2}$ for prediction to be 0.93 and 0.94 , respectively. The error rates for this parameter are lower than those reported by other authors using a different instrument in the NIR wavelength range from 900-1700 $\mathrm{nm}$ (Nogales-Bueno et al., 2014). Hence, a good capacity of correlation was achieved in numerous other works on prediction of TSS for wine and table grapes (González-Caballero et al., 2011; Parpinello et al., 2013).

The best prediction obtained in this study for $\mathrm{pH}$ was not as encouraging as those found in other studies. In the present study the highest value of $R_{\text {cal }}$ obtained was 0.58 with a RMSEC of 0.15 , which is much lower as compared to the results of Baiano et al. (2012) in which R value for white grapes was 0.80 . Similarly, in a study conducted by Cao et al. (2010) the models resulted in an R value of 0.97 for wine grapes. González-Caballero et al. (2010) on single berries of wine-grapes with coefficient of determination $\left(\mathrm{R}^{2}\right)$ of 0.64 in prediction using Vis-NIR range. The main reason for this difference on the results may be the method for setting the $\mathrm{Y}$ vector during the reference development. In all these studies the berries were individually juiced but in case of the present study a single value of $\mathrm{pH}$ was taken for a cluster of 15 berries. In case of TA, $R_{\text {cal }}$ of 0.71 with $R M S E C$ of $0.03 \%$ tartaric acid, and $R_{\text {pred }}$ of 0.78 with $R M S E P$ of $0.04 \%$ tartaric acid was yielded. These results presented a better performance as compared to González-

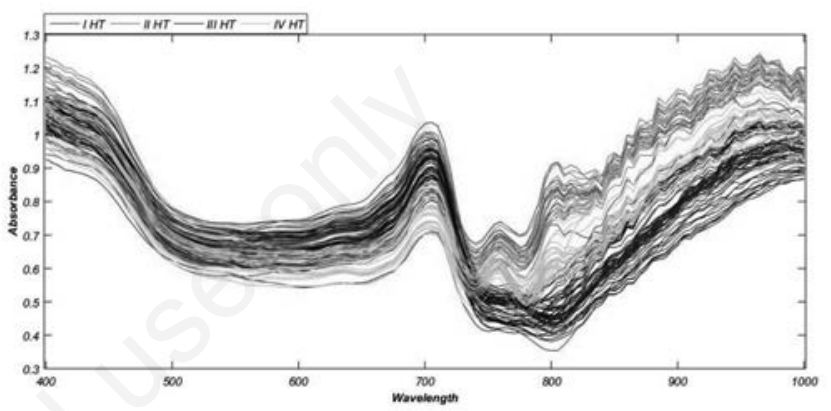

Figure 1. Row spectra of individual Italia table grape berries. HT, harvest time.

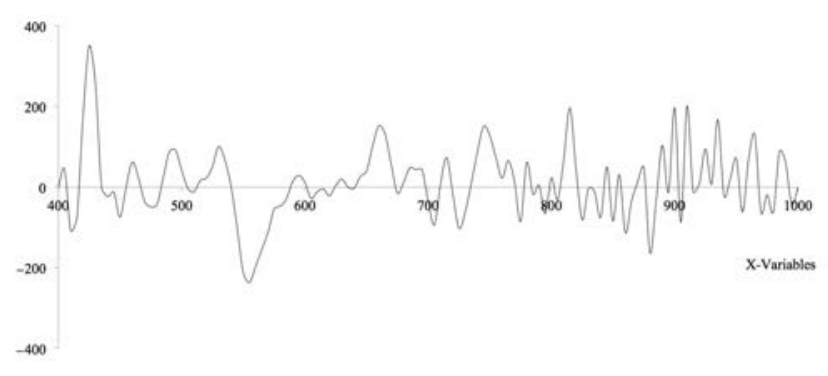

Figure 2. Regression coefficients of the partial least squares regression model for the calibration of total soluble solids on Italia table grapes.

Table 3. Performance of model of prediction for each quality attributes by optimal pre-treatment.

\begin{tabular}{|c|c|c|c|c|c|c|c|c|c|c|}
\hline Parameter & Pre-treatment & SD & & $\begin{array}{l}\text { alibratic } \\
0 \text { sampl }\end{array}$ & & & $\begin{array}{l}\text { redictio } \\
0 \text { sampl }\end{array}$ & & RPD & $\begin{array}{c}\text { PLS } \\
\text { factors }\end{array}$ \\
\hline & & & $R_{\text {cal }}$ & RMSEC & SEC & $R_{\text {pred }}$ & RMSEP & SEP & & \\
\hline TSS ( ${ }^{\circ}$ Brix) & $1^{\circ}$ Der. S. Golay & 1.85 & 0.91 & 0.77 & 0.78 & 0.88 & 0.95 & 0.97 & 1.92 & 13 \\
\hline $\mathrm{pH}$ & $1^{\circ}$ Der. S. Golay & 0.18 & 0.58 & 0.15 & 0.15 & 0.70 & 0.16 & 0.16 & 1.13 & 3 \\
\hline Titratable acidity (tartaric ac. g/100 g) & MSC & 0.03 & 0.71 & 0.03 & 0.03 & 0.78 & 0.04 & 0.03 & 0.86 & 7 \\
\hline Phenols (gallic ac. mg/100 g) & $2^{\circ}$ Der. S. Golay & 17.83 & 0.41 & 16.18 & 16.28 & 0.36 & 17.37 & 17.59 & 1.01 & 2 \\
\hline Antioxidant activity (Trolox mg/100 g) & MSC & 62.90 & 0.68 & 45.98 & 46.25 & 0.62 & 48.98 & 49.54 & 1.27 & 5 \\
\hline
\end{tabular}

SD, standard deviation; $R_{\text {cal }}$, R value for calibration set; RMSEC, root mean square error of calibration; SEC, square error of calibration; Rpred, R value for prediction set; RMSEP, root mean square error of prediction; SEP, standard error of prevision; RPD, residual prediction deviation; PLS, partial least squares regression; TSS, total soluble solids; MSC, multiplicative scatter correction. 
Caballero et al. (2010) work in which TA for the berries were measured over a wavelength range of 380-1650 nm giving an $\mathrm{R}^{2}$ of 0.33 in cross validation. The $\mathrm{R}$ values for TA in the present study are lower as compared to the study conducted by Baiano et al. (2012) in which the prediction values for TA were as high as 0.95 and 0.82 for white and red grapes, respectively, but similar to those obtained by Nogales-Bueno et al. (2014). The better results obtained in prediction for TA and $\mathrm{pH}$ compared to calibration, may be explained by the fact that models were not enough robust and may be by having selected by chance external data set which better described the correlation between spectra and analytic measure, compared to sample used for the calibration model.

Finally some consideration should be drawn on prediction performances of TSS, TA and PH models in relation to laboratory error. In fact, despite the lower $\mathrm{R}^{2}$ of TA and $\mathrm{pH}$ models, compared to TSS, prediction errors were very reasonable, if compared to laboratory errors, respectively, 0.59 for TSS, 0.10 for $\mathrm{pH}$ and 0.02 for TA. As general rule, SEP values should be as closer as possible to laboratory error, being considered excellent if not higher than 1.5 and good if around 2-3 time the laboratory error. In this case it can be observed as for all these 3 parameters the SEP was not higher than 1.6 times the laboratory error (for TSS), being even lower for TA and $\mathrm{pH}$. These findings suggest that the lower performances of the models may be attributed to the high variance of the modelled parameter in the juice, which may be expected since it is made from 15 berries, and to the error of the reference method. For antioxidant activity, the best statistics obtained were $R_{\text {cal }}=0.68$, $R M S E C=45.98 \mathrm{mg}$ Trolox $/ 100 \mathrm{~g}$ in calibration and $R_{\text {pred }}=0.62$, $R M S E P=48.98 \mathrm{mg}$ Trolox $/ 100 \mathrm{~g}$ in prediction, and no published studies reported the application of Vis-NIR spectroscopy on determination of antioxidant activity of grapes yet. In case of phenol content, lowest performances were observed in prediction, in particular a value of 0.41 for $\mathrm{R}$ in calibration and 0.36 in prediction, the same results were published by Kemps et al. (2010), in which the value of correlation $(\mathrm{R})$ in calibration ranged between 0.36 to 0.60 for various grape varieties. González-Neves et al. (2010) reported a value of $\left(\mathrm{R}^{2}\right)$ of 0.98 for total phenols in validation model using red grapes Graciano. Similar results were generated in a study conducted by Nogales-Bueno et al. (2014) in which the results of $\mathrm{R}^{2}$ values of 0.89 for red grapes, 0.80 for white grapes, and 0.77 for global models, were reported. Results demonstrated that, while good performances were observed for TSS, followed by $\mathrm{TA}, \mathrm{pH}$ and antioxidant activity, in agreement with the results of the other authors with research on grapes (Cao et al., 2010; González-Caballero et al., 2010, 2011; Baiano et al., 2012; Nogales-Bueno et al., 2014), a limited potential was seen in the performance of the PLS model in case of phenol content. In case of antioxidant activity, no comparison was possible since it has not been previously reported in any paper.

\section{Harvest times discrimination}

Results of the LDA allowed discriminating the 4 classes only by using 14 variables, showing a significant discrimination (Wilks'Lambda $0.000243313, \mathrm{P}<0.0000$ ) between the 4 classes. The variables selected, were 420, 580, 585, 630, 745, 760, 770, $780,800,805,865,870,925$ and $970 \mathrm{~nm}$ as showed in the discriminant Equation 1:

$0.360959 * 420+0.295888 * 580+0.557965 * 585-0.379512 * 630$

$-0.633662 * 745-0.585279 * 760+0.519507 * 770+$ $0.961174 * 780+0.595383 * 800+1.32246 * 805+0.592633 * 865+$

$0.29153 * 870-0.083511 * 925+0.537856 * 970$
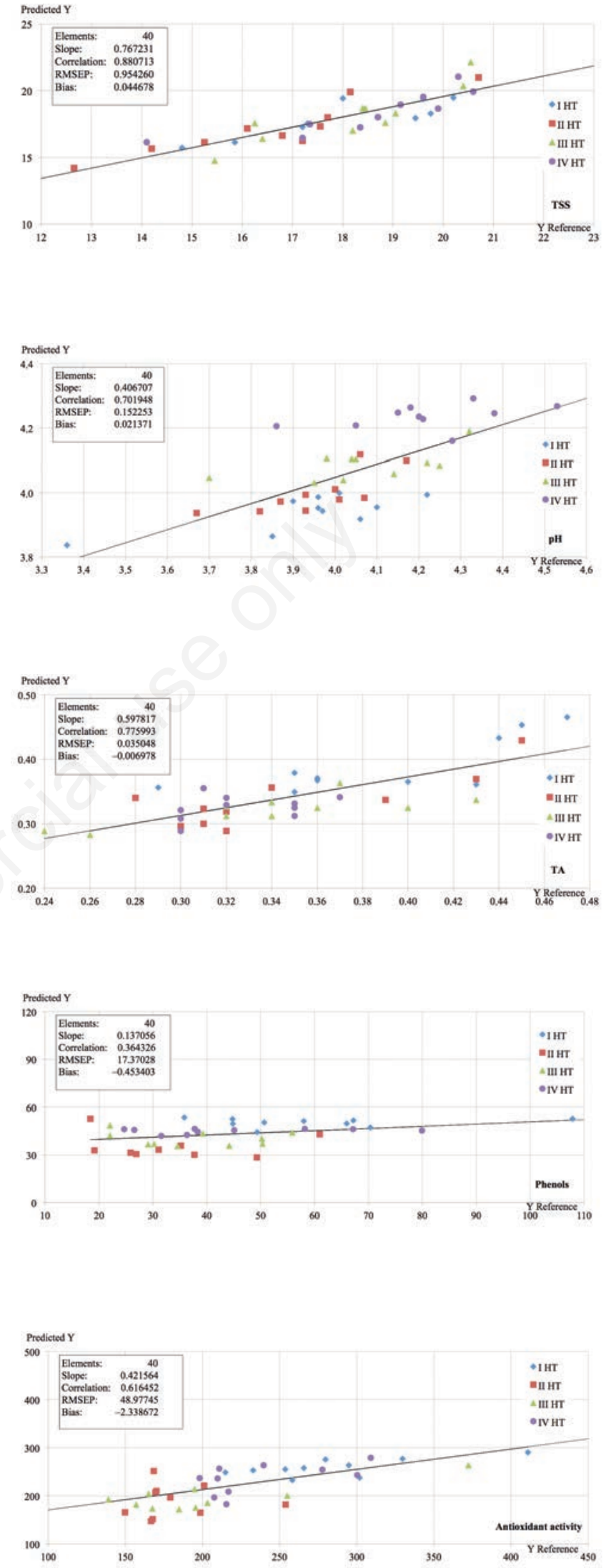

Figure 3. Performance of model of prediction for each quality attributes by optimal pre-treatment. TSS, of total soluble solids; TA, titratable acidity. 
The results of classification using the derived discriminant functions are shown in Table 4. Amongst the 120 observations used to fit the model, 119 (or 99.1667\%) were correctly classified, with only one sample belonging to II HT, being classified in I HT. These results confirmed the excellent capability of hyperspectral imaging to discriminate among grapes from different harvest time as reported by Piazzolla et al. (2013), but were optimised in term of number of wavelengths used for the model. Moreover this information were also used for further monitoring on quality changes over time on the plant. In fact, by using only the information contained in 14 wavelengths it was possible to predict the number of days for those grapes held on the plant after the first harvest. Models built to predict the days on the vine since the first harvest ( 0 day for HT1, 11 days for HT 2, 27 days for HT3 and 48 days for HT4) gave excellent for both calibration and external data set. In particular value of 0.98 for R, RMSEC of 3.29 days and SEC of 3.31 days were found in calibration, and comparable performances were obtained in prediction ( $\mathrm{R}$ of 0.98 , and SEP of 3.95 days). Relation of the spectra with time on the plants can be also observed in Figure 4 showing the predicted days on the plants for the external data set. These results confirmed that it was possible to discriminate grapes from different harvest times with a percentage of correct classification of $99.2 \%$ as shown in Table 4, but also suggested a possible way to monitor ripening on the plant by studying the spectra changes over time.

\section{Conclusions}

The results of this study confirm the suitability of using Vis-NIR hyperspectral scanner for reliable prediction of various analytes in table grapes, as already reported for wine grapes. Good prediction models were achieved for TSS, TA and $\mathrm{pH}$, and promising results were also obtained for antioxidant activity, which may be further improved. In addition to this, results of this study showed that

Table 4. Classification results by linear discriminant analysis at different harvest time for Italia grapes.

\begin{tabular}{lcccc} 
Qualitative groups & I HT & II HT & III HT & IV HT \\
I HT & 30 & 1 & - & - \\
II HT & - & 29 & - & - \\
\hline III HT & - & - & 30 & - \\
IV HT & - & - & - & 30 \\
\hline Percentage correctly classified & $100 \%$ & $96.67 \%$ & $100 \%$ & $100 \%$ \\
\hline
\end{tabular}

HT, harvest time.

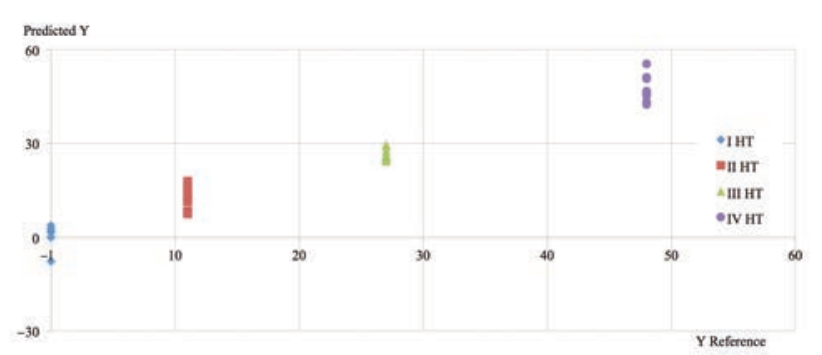

Figure 4. Performance of the linear discriminant analysis model to predict the numbers of days for grapes held on the plant after the first harvest. analysing spectra changes over time during on-vine holding of table grapes was possible to monitor ripening and to correctly classify grapes by harvest time, using only 14 wavelengths. These findings encourage further implementation of this method to monitor ripening of table grapes in the vineyard and better define most suitable harvest time also taking into account quality attributes more significant in terms of nutritional value of the product.

\section{References}

Baiano A., Terracone C., Peri G., Romaniello R. 2012. Application of hyperspectral imaging for prediction of physico-chemical and sensory characteristics of table grapes. Comput. Electron. Agric. 87:142-51.

Brand-Williams W., Cuvelier M.E., Berset C.L. 1995. Use of a free radical method to evaluate antioxidant activity. Food Sci. Technol. Lab. 28:25-30.

Cao F., Wu D., He Y. 2010. Soluble solids content and $\mathrm{pH}$ prediction and varieties discrimination of grapes based on visible-near infrared spectroscopy. Comput. Electron. Agric. 71:S15-8.

Chia K.S., Rahim H.A., Rahim R.A. 2012. Prediction of soluble solids content of pineapple via non-invasive low cost visible and shortwave near infrared spectroscopy and artificial neural network. Biosyst. Engine. 113:158-65.

Cliff M.A., Dever M.C., Reynolds A.G. 1996. Descriptive profiling of new and commercial British Columbia table grape cultivars. Am. J. Enol. Viticult. 47:301-8.

Costa G., Noferini M., Fiori G., Torrigiani P. 2009. Use of Vis/NIR spectroscopy to assess fruit ripening stage and improve management in post-harvest chain. Fresh Prod. 1:35-41.

Crisosto C.H., Crisosto G.M., Metheney P. 2003. Consumer acceptance of 'Brooks' and 'Bing' cherries is mainly dependent on fruit SSC and visual skin colour. Postharv. Biol. Technol. 28:159-67.

Dambergs R., Cozzolino D., Cynkar W., Janik L., Gishen M. 2006. The determination of red grape quality parameters using the LOCAL algorithm. J. Near Infrared Spectrosc. 14:71.

FAO, 2009. FAOSTAT Data. Food and Agricultural Organisation of United Nations: Economic And Social Department: The Statistical Division. Available from: http://faostat.fao.org

Fernandes A.M., Oliveira P., Moura J.P., Oliveira A.A., Falco V., Correia M.J., Melo-Pinto P. 2011. Determination of anthocyanin concentration in whole grape skins using hyperspectral imaging and adaptive boosting neural networks. J. Food Engine. 105:216-26.

Fernández-Novales J., López M.I., Sánchez M.T., Morales J., González-Caballero V. 2009. Shortwave-near infrared spectroscopy for determination of reducing sugar content during grape ripening, winemaking, and aging of white and red wines. Food Res. Int. 42:285-91.

Ferrer-Gallego R., Hernández-Hierro J.M., Rivas-Gonzalo J.C., Escribano-Bailón M.T. 2011. Determination of phenolic compounds of grape skins during ripening by NIR spectroscopy. Food Sci. Technol. Lab. 44:847-53.

González-Caballero V., Pérez-Marín D., López M.I., Sánchez M.T. 2011. Optimisation of NIR spectral data management for quality control of grape bunches during on-vine ripening. Sensors 11:6109-24.

González-Caballero V., Sánchez M.T., Fernández-Novales J., López M.I., Pérez-Marín D. 2012. On-vine monitoring of 
grape ripening using near-infrared spectroscopy. Food Anal. Methods 5:1377-85.

González-Caballero V., Sánchez M.T., López M.I., Pérez-Marín D. 2010. First steps towards the development of a non-destructive technique for the quality control of wine grapes during on-vine ripening and on arrival at the winery. J. Food Engine. 101:158-65.

González-Neves G., Gil G., Ferrer M., Charamelo D., Balado J., Bochicchio R., Gatto G., Tessore A. 2010. Prediction of the colour and polyphenolic composition of the young red wines from the phenolic potential of the grapes. Int. J. Food Sci. Technol. 45:1843-51.

Guelfat-Reich S., Safran B. 1971. Indices of maturity for table grapes as determined by variety. Am. J. Eno. Viticult. 22:13-8.

Ignat T., Schmilovitch Z., Fefoldi J., Steiner B. Alkalai-Tuvia S. 2012. Non-destructive measurement of ascorbic acid content in bell peppers by VIS-NIR and SWIR spectrometry. Postharvest Biol. Technol. 74:91-9.

Jayasena V., Cameron I. 2008. ${ }^{\circ}$ Brix/acid ratio as a predictor of consumer acceptability of Crimson Seedless table grapes. J. Food Qual. 31:736-50.

Kemps B., Leon L., Best S., De Baerdemaeker J., De Ketelaere B. 2010. Assessment of the quality parameters in grapes using VIS/NIR spectroscopy. Biosyst. Engine. 105:507-13.

Nicolaï B.M., Beullens K., Bobelyn E., Peirs A., Saeys W., Theron K.I., Lammertyn J. 2007. Nondestructive measurement of fruit and vegetable quality by means of NIR spectroscopy: a review. Postharv. Biol. Technol. 46:99-118.

Nogales-Bueno J., Hernández-Hierro J.M., Rodríguez-Pulido F.J., Heredia F.J. 2014. Determination of technological maturity of grapes and total phenolic compounds of grape skins in red and white cultivars during ripening by near infrared hyperspectral image: a preliminary approach. Food Chem. 152:586-91.

Parpinello G.P., Nunziatini G., Rombolà A.D., Gottardi F., Versari A. 2013. Relationship between sensory and NIR spectroscopy in consumer preference of table grape (cv Italia). Postharv. Biol. Technol. 83:47-53.

Pedro A.M., Ferreira M.M. 2007. Simultaneously calibrating solids, sugars and acidity of tomato products using PLS2 and NIR spectroscopy. Analyt. Chim. Acta 595:221-7.

Peppi M.C., Fidelibus M.W., Dokoozlian N. 2006. Abscisic acid application timing and concentration affect firmness, pigmentation, and color of flame seedless' grapes. HortSci. 41:1440-5.

Piazzolla F., Amodio M.L., Colelli G. 2013. The use of hyperspectral imaging in the visible and near infrared region to discriminate between table grapes harvested at different times. J. Agricult. Engine. 44:49-55.

Piva C.R., Garcia J.L.L., Morgan W. 2006. The ideal table grapes for the Spanish market. Rev. Brasil. Fruticult. 28:258-61.

Porep J., Mattes A., Nikfardjam P., Kammerer D. Carle R. 2015. Implementation of an on $\square$ line near infrared/visible (NIR/VIS) spectrometer for rapid quality assessment of grapes upon receival at wineries. Austral. J. Grape Wine Res. 21:69-79.

Singleton V.L., Rossi J.A. 1965. Colorimetry of total phenolics with phosphomolybdic-phosphotungstic acid reagents. Am. J. Enol. Viticult. 16:144-58.

Slaughter D., Barrett D., Boersig M. 1996. Nondestructive determination of soluble solids in tomatoes using near infrared spectroscopy. J. Food Sci. 61:695-7.

Sonego L., Lurie S., Zuthi Y., Kaplonov T., Ben-Arie R., Kosto I. 2002. Factors affecting taste scores of early season seedless table grape Cv. Mystery and prime. J. Agricult. Food Chem. 50:544-8.

Wei X., Sykes S.R., Clingeleffer P.R. 2002. An investigation to estimate genetic parameters in CSIRO's table grape breeding program. 2. Quality characteristics. Euphytica 128:343-51.

Wu G., Huang L., He Y. 2008. Research on the sugar content measurement of grape and berries by using Vis/NIR spectroscopy technique. Guang Pu Xue Yu Guang Pu Fen Xi 28:2090-3. 